\title{
On Preverbal Negation in Sicilian and Syntactic Parasitism
}

\section{Jacopo Garzonio}

University of Venice Ca' Foscari

garzonio@unive.it

\section{Cecilia Poletto}

Goethe University Frankfurt

poletto@em.uni-frankfurt.de

Received: 21-04-15

Accepted: 17-06-15

\section{Abstract}

In this paper we describe two different cases of $\mathrm{CP}$ negation in some Sicilian dialects. The first element is a left periphery adverb that is derived from a grammaticalized negative cleft sentence; the second is a negative head which is overtly realized when a higher functional projection is activated. While the two items display a set of relevant differences, it is argued that they exemplify two possible cases of syntactic parasitism. The term is used to indicate that either the position of the parasitic element is "borrowed" from another type of category (in the present case it is Focus) or the presence of a given head (a negative morpheme in this case) is licensed by the presence of a different item in a close structural position.

Keywords: Negation; Italian Dialects; Sicilian

\section{Table of Contents}

1. Introduction

2. Negative Clefts and Feature Parasitism
3. Negative Heads in the $\mathrm{CP}$ and Structural Parasitism

4. Negation in the $\mathrm{CP}$ 


\section{Introduction}

Italo-Romance varieties display a very rich typology of negation markers displaying a high degree of variation in relation to their lexical category, their syntactic behavior (cf. among many others Zanuttini (1997) and Manzini and Savoia (2005)), and their diachronic origin. Much recent work in formal frameworks has focussed on low, i.e. post-verbal negative adverbs and on some specific areas in the Northern Italian dialectal domain. In this paper we describe two less studied negative items from a Southern Italian dialectal domain, Sicilian.

The two cases that we observe share the interesting property of involving the $\mathrm{CP}$ level of the clause. Even more interestingly, the negative markers we analyze can be seen as examples of syntactic parasitism, an intuitive notion that will be discussed in the final part of the paper. The first type of syntactic parasitism (analyzed in section 2) is defined by the fact that the position of the negative marker remains the same even when its special emphatic meaning is lost, i.e. negation still exploits the structural position of Focus even when no Focus is involved. This fact is particularly interesting since it hinges on the question as to whether there exists an independent NegP or not.

The second syntactic parasitism that we take into consideration in section 3 , labeled "structural parasitism", involves the activation of a given projection in the CP only if the CP is already active; in our specific case the insertion of a negative head in the $\mathrm{CP}$ layer occurs only when the $\mathrm{CP}$ contains some other lexical element, either moved to or merged in the Left Periphery. This phenomenon is purely syntactic in nature, since, as we will show, it is blind to the semantic properties of the elements involved. In section 4 we conclude the article with some discussion about the properties of these negative items in the CP field.

\section{Negative Clefts and Feature Parasitism}

In many languages standard negation (intended as the "basic means that languages have for negating declarative verbal main clauses" (Miestamo $(2007,553)$ ) is expressed by a negative matrix verb that takes a clausal complement. Following Payne's (1985) survey, these items are known as "higher negative verbs" in the typological literature, and are generally related to the diachronic process known as the Croft Cycle (Croft (1991)), where a negated existential verb is reduced to a negative head or a negative adverb. ${ }^{1}$

We would like to thank Paola Benincà, Silvio Cruschina, Mair Parry, Diego Pescarini, Silvia Rossi, Raffaella Zanuttini, the audience of the CIDSM 8 conference (PaduaVenice, 20-22.06.2014) and two anonymous reviewers for all the comments, suggestions and discussion. Although the article has been written jointly by the two authors, Jacopo Garzonio is responsible for sections 2 and 4, Cecilia Poletto for sections 1 and 3 .

A possible example of higher negative verb is found in Tongan (Churchward (1953, 56), cited by Miestamo (2007)):

$\begin{array}{llllll}\text { a. na'e 'alu } & \text { 'a } & \text { siale. } & & \\ & \text { PST go } & \text { ABS } & \text { Siale } & & \\ \text { 'Siale went.' } & & & & \\ \text { b. na'e 'ikai ke } & \text { 'alu } & \text { 'a } & \text { siale. } \\ & \text { nST NEG } & \text { SBJV } & \text { go } & \text { ABS } & \text { Siale } \\ & \text { 'Siale didn't go.' } & & & \end{array}$


In this section we take into consideration negative clefts in standard Italian (Bernini (1992)) and compare their semantics and their syntactic behavior with those involving Sicilian neca (Cruschina (2010)), a negative adverb derived from a negative cleft through a process very similar to the Croft Cycle. Both items are not the standard negative markers in their respective grammars, and they display some relevant differences from an interpretive point of view. As it will be made clear in the following sections, the reanalysis process is possible only because the negative cleft expresses at the same time negation and focus. When focus is lost, negation remains in exactly the same position. ${ }^{2}$

\subsection{On the 'non è che' Construction in Standard Italian}

The sentence in (1) provides an example of the construction we examine in this section (see also Bernini (1992)); the matrix clause is formed by the negation, the copula and the declarative complementizer che.

Non è che sia stupido, (è che non studia abbastanza).

not is that is stupid, (is that not studies enough)

'It is not that he is stupid. He does not study enough.'

For the sake of clarity and simplicity we use the term "negative cleft" to define this construction. However, it must be pointed out that the cases we are considering are different from those where a constituent of the embedded clause is raised to the precomplementizer position, as in (2):

Non è Gianni che ha aperto la porta.

not is John that has open the door

'It is not John that opened the door.'

In (2) the subject of the embedded clause is raised to the matrix clause where it receives (negative) focus. Contrary to such "partial" cleft structures, there is not a prominent constituent or sub-part of the embedded clause in the cases we are dealing with here. The same is true of positive cleft, which are also possible:

Context: Ma come, non vuoi venire alla festa?

'You don't want to come to the party, why so?'

È che non mi sento bene.

is that not me feel well

'It is that I do not feel well.'

Notice that in the second sentence it is the negative verb that is marked for past tense, while the lexical verb 'to go' is introduced by the subordinate marker ke.

2 As pointed out by an anonymous reviewer, this process could be seen as an interesting case of syntactic development (and associated structural representations) lagging behind semantic developments. The so-called "semi-auxiliaries" in Romance can be analyzed as another case of this type. This could represent a problem for a classic cartographic approach and its requirement of isomorphic mapping between syntax and interpretation (one feature corresponds to one projection). However, we argue that negation per se is not a feature but a complex semantic item, and since Focus is an "ingredient" of negation, a Focus position can contain a negative marker. 
That negative clefts are different with respect to both partial and positive clefts is shown by the fact that in negative clefts the verb of the embedded clause usually appears in the subjunctive mood (but the indicative is tolerated as well), while in the other types of clefts only the indicative is admitted:

(4) a. Non è che Gianni abbia/ha aperto la porta... not is that John has.SBJV / has.IND opened the door 'It is not that John opened the door...'

b. *Non è Gianni che abbia aperto la porta. not is John that has.SBJV opened the door.

c. $\quad * \grave{E}$ che Gianni abbia aperto la porta. is that John has.SBJV opened the door.

A second difference is that in the case of negative clefts the copula may be optional while in the case of positive or partial clefts it is mandatory:

(5) a. Non che Gianni abbia aperto la porta... not that John has opened the door. 'It is not that John opened the door...'

b. *Non Gianni che ha aperto la porta. not John that has opened the door

c. $\quad *$ Che Gianni ha aperto la porta. that John has opened the door

Interestingly, when the copula in the matrix is absent, the subjunctive for the embedded verb is strongly preferred.

Beside the properties that differentiate our construction from standard negative clefts, it can be shown that the matrix portion behaves as a truly independent clause: the copula can optionally be inflected for tense, aspect and modality. The examples in (6) show, respectively, a past imperfective and a modal future (dubitative) copula: ${ }^{3}$

(6) a. Non (era) che non volesse partire (...non aveva il biglietto). not was that not wanted leave.INF (not had the ticket) 'It wasn't that he did not want to leave. He had not the ticket.'

b. Non (sarà) che non volesse partire (...probabilmente non aveva il biglietto). not will.be that not wanted leave.INF (probably not had the ticket) 'I doubt that he did not want to leave. Very likely he had not the ticket.'

Furthermore, the matrix portion can contain focus adverbs like solo 'only' or neanche 'not even, neither', and also some high sentential adverbs like sicuramente 'surely':

3 Positive clefts also behave as negative clefts in this respect. The distinction between positive and negative clefts could indeed be due to the presence of the negative marker, which licenses the subjunctive in the embedded clause. 
(7) a. Non *(è) solo che non studi (...si distrae troppo). not is only that not studies (REFL=distracts too.much)

'It is not only that he does not study. He is too much inattentive.'

b. Non *(è) neanche che non studi (...proprio non capisce). not is that not.even that not studies (just not understands) 'It is not even that he does not study. He just do not understand.'

c. Non *(è) sicuramente che non studi (...anzi!...proprio non capisce). not is surely that not studies (actually just not understands) 'Surely it is not that he does not study...quite the contrary!...He just do not understand.'

It should be noticed that, while the copula is optional in cases like those in (5), it cannot be omitted if there is an adverb.

We consider all these properties as evidence that this construction has a complete bi-clausal structure where also the main clause has a complete structural tree, crucially including TP, as shown by the fact that the copula can be inflected in its past form. A preliminary analysis is represented in (8):

$$
\text { [CP non è [CP che [TP sia stupido ]]] }
$$

However, some semantic properties must also be taken into account in order to provide a more adequate characterization of this construction and to better understand its relation with grammaticalized forms like Sicilian neca.

Borrowing from discourse analysis terminology, the Italian non $\grave{e}$ che construction corresponds to the negative version of what is commonly referred to as "inferential cleft". These elements have been analyzed for English by Delahunty (1995) and for Spanish by Delahunty and Gatzkiewicz (2000). These studies report similar cases also from many other languages, suggesting that constructions with an analogous discourse function are present in all natural languages. From the point of view of discourse analysis, the main property of inferential clefts is that they do not negate an assertion but an inference, which is potentially available to the interlocutor given the context (a proposition in the prior sentences, but also propositions derived from beliefs or stereotypes considered as common knowledge). More precisely, a negative inferential cleft does not operate on the truth value of the embedded clause, but on its discourse relevance. This is clearly shown by the fact that potentially the embedded clause can be true, as for instance in (7b), which is not contradictory even if the mentioned person spends a lot of time studying: the fact is presented as non relevant for the discussed problem. ${ }^{4}$ This property is strictly connected to the fact that the non è che construction, like the corresponding constructions in other languages, is used when two claims are contrasted. In most examples provided above the inference given by the non è che construction is contrasted with the following sentence. Another case where a negative cleft of this type is used in Italian is in conditionals like the following:

$4 \quad$ Delahunty $(1995,357)$ reports for English the following example from I. Murdoch's The Black Prince: "On principle I usually avoid introducing my friends and acquaintances to each other. It is not that one fears treachery, though of course one does. What human fear is deeper? But endless little unnecessary troubles usually result from such introduction". 
Non è che, se io non telefono, tu non ti fai sentire. not is that if I not call you not you=make hear.INF

'Even if I do not call you, it is not right if you do not stay in touch.'

In this case the negated inference corresponds to the implication expressed by the conditional. While we are not interested here in all the possible functions of negative inferential clefts, it is clear that they are sentential focus constructions, as confirmed by the possibility to use focus adverbs: the embedded proposition is extracted from the set of potentially relevant propositions, and then contrasted, that is negated, with the really relevant proposition, at least according to the speaker's epistemic and evidential interpretation. This means that, at the semantic-syntactic interface, these constructions are characterized by the encoding of two features: a focus feature and a modality feature related to the speaker's point of view. ${ }^{5}$ Taking this into account, we modify the basic representation in (8) in the following way: like in other clefts (see Belletti (2008)), the embedded CP is a full clause, while the matrix is a reduced CP. The whole embedded $\mathrm{CP}$ is moved to a Focus position (likely the one located in the vP periphery of the matrix be). The negative marker is endowed with a modal functional feature related to the speaker (for our purposes its exact position in the matrix clause is not relevant).

$$
\text { [TP } \operatorname{non}_{(\text {Mod) }} \text { è [FocusP [CP che sia stupido] [vP essere [ep-che sia stupide ]]]] }
$$

That the negative marker has a modal feature related to the inferential interpretation is shown by the fact that it can be substituted by a different lexical item, namely the negative adverb mica. In this case the copula can be absent (unless there is a focus adverb) and the embedded verb displays subjunctive mood, like in the case mentioned above with non. The crucial property is that, in these cases, mica does not interfere with the presence of scalar and temporal implicatures in the embedded clause. We discuss this issue in the next section where we compare non è che with the adverb mica. ${ }^{6}$

\subsection{On the Differences between 'non è che' and 'mica'}

The negative adverb mica (Cinque (1976)) is a postverbal negative marker that is normally used to negate an expectation of the interlocutor. Since it is not used to simply negate an assertion, it is not a standard negative marker. Cinque (1976) pointed out that mica cannot be used if the expectation contradicts a presupposition of the clause (this is the reason mica is in some cases labeled as "presuppositional negation"). Penello and Pescarini (2008) also noticed that in some cases mica cannot be used even though there is no blocking presupposition: it is the case of sentences containing a temporal or scalar implicature: ${ }^{7}$

5 See Giorgi (2010) on the syntactic encoding of the Speaker.

6 We do not examine yes/no interrogative clefts here, but it is important to point out that also in this case there appears to be a dichotomy between the positive and the negative variant, as the former is very marginal in Italian and Italian dialects.
(i) a.
Non è che hai una penna?
(Italian)
not is that have a pen
'Do you have a pen, by chance?'
b. $\quad * / *$ ?È che hai una penna?
is that have a pen

It should be pointed out that, while the scalar implicature is completely incompatible with mica, temporal expressions like 'since three years' are not excluded. However, as 

a. \%Giovanni non mangia mica pasta da tre anni. John not eats mica pasta since three years 'It's three years that John does not eat pasta.'
b. $\quad \%$ Non ha mica mangiato neanche la zucca not has mica eaten not.even the pumpkin 'He has not eaten even the pumpkin.'

(P\&P ex. (15c))

(P\&P ex. (19a))

What is relevant for our discussion here is that, even if both mica and the non $\grave{e}$ che construction do not negate an assertion, they have different effects: mica interacts with the truth value of the proposition and its presuppositions and the implicatures it activates; on the other hand non è che is independent of the truth value of the embedded proposition and only negates its contextual relevance. While it is not possible to check its interaction with presuppositions, the point we are discussing is shown by the fact that non è che is compatible with implicatures:

(12) a. Non è che Gianni non mangia pasta da tre anni (mangia poco in generale) not is that John not eats pasta since three years eats little in general 'It is not that he hasn't eaten pasta in three years. He eats little in general'

b. Non è che non abbia mangiato neanche la zucca (non ha proprio mangiato) not is that not has eaten not.even the pumpkin not has really eaten 'It is not that he has not eaten even the pumpkin. He ate nothing.'

These examples suggest that this is possible because the claim expressed by the second sentence implies somehow the content of the negated inference. Crucially, when mica is used in a negative cleft, this does not interfere with temporal and scalar implicatures: ${ }^{8}$
(13) a. Mica che Gianni non mangi pasta da tre anni... mica that John not eats pasta since three years
b. Mica che non abbia mangiato neanche la zucca... mica that not has eaten not.even the pumpkin

On the basis of these examples we can assume that when mica appears in a negative cleft like those in (13) it has the same interpretation of the negative marker non. More precisely, we have argued that in these cases the negative element simply negates the relevance of the inference expressed by the embedded clause (independently from its polarity). Keeping in mind this analysis we can now examine the behavior of elements derived from negated clefts, like Sicilian neca.

Penello and Pescarini (2008) argue, the expectation licensing mica (e.g. 'Giovanni eats pasta') is as a general case of the implicature activated by the temporal expression ('Giovanni ate pasta even before three years ago'), and thus it is normally negligible from the pragmatic point of view.

8 The examples in (13) must not be confused with the following ones, that display a further property of mica, namely the possibility to be used in preverbal position. When mica is simply preverbal, it is still imcompatible with implicatures:
(i)
a. $\%$ Mica mangia pasta da tre anni. mica eats pasta since three years
b. \%Mica ha mangiato neanche la zucca. mica has eaten not.even the pumpkin 


\subsection{When Clefts are Grammaticalized. On Sicilian 'neca'}

Cruschina $(2010 ; 2015)$ discusses many cases of Sicilian adverbs derived through the grammaticalization and univerbation of complex structures. Among these adverbs, some discussion is dedicated to neca 'not (at all)'. This element is derived through the reduction and grammaticalization of un jè ca 'it is not that', that is, of the structure 'negation-copula-complementizer' of a negative cleft $(n-\grave{e}-c a)$. Unlike the productive negative cleft construction, neca displays no tense/aspect alternations:
a. $\quad * \mathrm{~N}$ era ca ci vonsi jiri.
(Mussomeli)
not was that there=wanted.3PL go.INF
'They did not wanted to go there.'
b. Unn'era ca ci vonsi jiri...
not was that there=wanted.3PL go.INF
c. Neca ci vonsi jiri.
not there $=$ wanted.3PL go.INF

According to Cruschina (2010: 31), its meaning is similar to the one of Italian mica. In other words, it characterizes the negated proposition as a wrong expectation made by the interlocutor:

Sta lezioni neca si capisci.

this lesson not REFL=understands

'(Contrary to what you think) one does not understand this lesson.'

This interpretation is confirmed if we use the test illustrated in the previous section: neca is not compatible with elements introducing a scalar or a temporal implicature (unless the latter corresponds to the intended expectation):
a. $\quad$ *Neca mancu a cucuzza si mangia'.
(Mussomeli)
not not.even the pumpkin REFL=ate. $3 \mathrm{SG}$
'He didn't eat even the pumpkin.'
b. $\%$ Neca dormi di quannu arriva'.
not sleeps of when arrived.3sG
'He does not sleep since when he arrived.'

Such behavior is somehow unexpected, because neca does not appear in the postverbal positions of Italian mica: these data suggest that the "presuppositional" interpretation of a negative marker is not directly linked to its syntactic distribution (a fact also pointed out by Ledgeway (2015)). On the other hand, even if neca precedes the proposition it negates, it has not the inferential interpretation of the negative cleft from which it historically derives.

The analysis we propose to explain the properties of neca is based on the idea that negations are semantically (and often syntactically) complex items. In particular, we would like to propose that one of the semantic operations involved in the interpretation of Focus, namely the creation of a set, is similar to one of the operations 
involved in the interpretation of negation. ${ }^{9}$ Furthermore, the case of neca shows that this type of reanalysis can correspond to the univerbation of the whole matrix $\mathrm{CP}$. The fact that clefts have the tendency to move from bi-clausal to mono-clausal structures is well known in the literature. For instance Munaro and Pollock (2005) show that in French there are both types of structures and that in the case of monoclausal clefts, what originally was the main clause has become a vP located in one of the Specifiers of the left periphery of what originally was the embedded clause. The analysis we propose for the diachronic development of neca follows exactly the same line of thought and is represented in (17): the complex negation-copula-complementizer sequence is reanalyzed as a unique functional projection (we assume it is a Focus projection), with respectively the negative marker and the copula in the specifier and the complementizer in the head (17a) ${ }^{10}$; then the whole FP is lexicalized as a single functional word (a wellknown development in diachronic morpho-syntax)(17b):

$$
\begin{array}{ll}
\text { a. } & {\left[\text { Spec Focus }[\text { unn è }]\left[\text { Focus }^{\circ} \text { ca }\right][\text { TP ... }]\right]} \\
\text { b. } & {[\text { FocusP neca }[\text { TP ...]] }}
\end{array}
$$

Notice that although neca has become a single word, it still sits in the same position originally occupied by unnè, namely FocusP. ${ }^{11}$

9 We will not expand on this point, as it requires a new analysis of the semantics of negation, which rejects the standard idea that negation in natural languages is similar to the operator found in formal logics, i.e. a single operator which has scope on the whole proposition, but consists of a number of different semantic operations which result into negating the proposition. More precisely, syntactic negation can be seen as a complex phrase, consisting of several ordered projections and presumably merged with $v$ P. See Poletto (2008) for a preliminary version of this "split-NegP" analysis.

This analysis is parallel to the analysis of the wh item qu'est-ce que in Modern French proposed by Munaro and Pollock (2005). It is another case where a cleft containing a focus projection is re-analyzed as a single projection. See Harris and Campbell (1995) for a general discussion of syntactic re-analysis.

11 This is confirmed by the following tests (Silvio Cruschina, p.c.):

a) neca is not compatible with a fronted XP, be it a contrastive focus or an informational focus.
(i) a.
*I piatta neca purtavu.
(Mussomeli)
the dishes not brought
'It is the dishes that I did not bring.'
b. $\quad *$ cu Mariu neca parlavu.
with Mario not spoke
'It is with Mario that I did not speak.'

b) neca is compatible with a left dislocated XP and must follow it.

(ii) a. I piatta, neca i purtavu.

the dishes not them brought

'I did not bring the dishes.'

b. $\quad$ Neca i piatta i purtavu.

We do not discuss here the possibility that neca occupies the head of FocusP. If this is the case, the phenomenon is an instance of the more general Head Preference Principle (Van Gelderen 2004). More precisely, we have a Spec > Spec > Head development. 
This observation has some interesting consequences for a general theory about the syntax of negation and also for the study of the Jespersen Cycle, the diachronic development that introduces new negators in a language (see, among many others, van der Auwera (2009; 2010) and Willis, Lucas and Breitbarth (2013)). Sicilian neca is a negative item that is grammaticalized without changing its position and without the weakening of the standard negative marker. This contrasts with the diachronic path of minimizers and n-words that become negative markers: these elements start inside the VP and are grammaticalized as adverbs occupying specifier positions in the sentential functional layer (Zanuttini (1997); Garzonio and Poletto (2010)). On the contrary neca stays in the left periphery of the clause, where it occupies a Focus position. ${ }^{12}$

\section{Negative Heads in the CP and Structural Parasitism}

In this section we examine a different kind of parasitism observable in the negative system of some Sicilian dialects. While the case of neca presented in the previous sections involves the exploitation of a specific syntactic position in relation to the grammatical feature associated with that position, there are cases where the presence of a negative morpheme is triggered in co-occurrence with elements in the clause structure independently of their feature construal.

\subsection{On the 'un/nun' Alternation in some Sicilian Dialects}

In Sicilian varieties the standard negative marker is a pre-verbal clitic, like in most Central and Southern Italian dialects. This clitic has two forms: in the dialects of Eastern Sicily this form is non or nun, while in other dialects it is un. In Garzonio and Poletto (2014b) it is argued that in some of the dialects that display the form nun/non the negative marker is bi-morphemic, as it is reduced to $n$ - when it co-occurs with preverbal object clitics:

(18) a. S'avissi statu cchiu attentu, non fussi a ssu punto.(Catania, G\&P: (14a)) if had.2SG been more careful not would.be.2SG at this point 'If you had been more careful, you would not be in this situation.'

b. Penzu ca rumani n o pottu.
think.1SG that tomorrow not=it bring.1SG

(Catania, G\&P: (15a))

'I think that I will not bring it tomorrow.'

The phenomenon cannot be purely phonological, as it targets only the preverbal negation, and not other items with the same phonological form in similar contexts. ${ }^{13}$ The analysis proposed by Garzonio and Poletto (2014b) assumes that object clitics

12 Leaving aside some differences, a similar phenomenon is the origin of the development of negative marker manka in the dialect of Rionero in Vulture, described by Garzonio and Poletto (2014a): this item is originally a negative focus marker, corresponding to Italian manco 'not even, neither', that becomes the standard negative marker of this variety.

13 We refer to Garzonio and Poletto (2014b) for a thorough discussion of this phenomenon and of similar facts in Old Italian and Old Sicilian varieties. It is not completely clear if the bi-morphemic negation analysis can be extended also to the Lazio dialects that display the Lex Porena (the cancellation of the initial [1] of clitics and determiners and the successive vocalic coalescence in some syntactic configurations; cf. Marotta (20022003)). 
compete with the lower negative morpheme for the same structural position in the clitic hierarchy. ${ }^{14}$ The dialects that have the form $u n$ do not display similar alternations, and when un co-occurs with preverbal clitics it simply assimilates:

(19) a. S'avissi statu chiu attentu, unn'avissi arrivatu a stu puntu. (Palermo,

G\&P ex. (29b))

if=were. $3 \mathrm{SG}$ been more careful not would.have.3SG arrived to this point

'If he had been more careful, he would have not been in this situation.'

b. Pensu ca rumani unn u puortu. (Palermo, G\&P ex. (33))

think.1SG that tomorrow not=it bring.1SG

'I think that I will not bring it tomorrow.'

However, there exists a third type of negative marker not discussed in Garzonio and Poletto (2014b). In some dialects (we have observed this phenomenon in the varieties of Sciacca and of S. Biagio Platani, both in the province of Agrigento, in the south-west of Sicily) the form of the preverbal negative marker is normally $u n:^{15}$
a. Iddu un curri mai.
(Sciacca)
he not runs never
'He never runs.'
b. Un sacciu cu parlau cu Maria.
not know.1SG who spoke.3SG with Mary
'I don't know who spoke with Mary.'

In these varieties, when un precedes preverbal clitics, it behaves like in other varieties that have the same form, i. e. un does not change or assimilate:
a. Un c'è nuddu pi strada.
(Sciacca)
not there=is nobody for road
'Nobody is on the road.'
b. Un ti preoccupari.
not you worry.INF
'Don't worry.'
c. Sta fimmina um-mi cala.
this woman not=me pleases
'I don't like this woman.'
(Sciacca)
(S. Biagio Platani)
14 This analysis has some interesting consequences for the idea that negation has a complex internal structure. It is implied that object clitics and negation share some type of feature, which is not the [focus] feature we have discussed in relation to neca, but more likely an [Existential] feature (see Cattaneo 2009 and Manzini and Savoia (2005) on the internal structure of Romance clitics)).
15 The examples of Sciacca are taken from the ASIt database (http://asit.maldura.unipd.it/index.html), while those of S. Biagio Platani are from the AIS (Jaberg and Jud (1928-1940)). We are aware that some specific syntactic contexts are not tested, as pointed out by an anonymous reviewer, but our goal here is to provide a first characterization of the phenomenon before further research with additional data collection.


However, if a complementizer is present, chi, with finite verb forms, and $d i$ and $p i$, with infinitivals, the form of the preverbal negation is $n u n:^{16}$
a. Pensu di nun puttarlu dumani.
(Sciacca)
think.1SG of not bring.INF=it tomorrow
'I think that I will not bring it tomorrow.'
b. Pi non chiamari i so frati i musicisti la festa fu nuiusa. (Sciacca) for not call.INF the his brothers the musicians the party was boring 'Since his brothers did not call the musicians, the party was boring.' that not=her found.1PL
'...that we had not found her.'
c. ...chi nul-la truvassimu.
(S. Biagio Platani)

This distribution cannot be explained by means of a phonological rule, as it is not the presence of a word before the negation that triggers the presence of the nun/non form. This is shown by (20a) for Sciacca, repeated here as (23a), and (23b) for S. Biagio Platani; in both examples there is a pronoun as subject of the clause and the form of the preverbal negation does not display the additional initial nasal segment:
a. Iddu un curri mai.
(Sciacca)
he not runs never
'He never runs.'
b. $\quad$...iddu um fussi kuntenti. (S. Biagio Platani)
he not was happy
'...he was not happy.'

Interestingly, the form with the additional nasal appears also in yes/no questions introduced by a negation:
Nun l'hai ancora accattatu?
not it=have. 2 SG yet bought
(Sciacca)
'Haven't you bought it yet?'

Examples like (24) are further evidence that the phenomenon has a syntactic grounding: the negation is in absolute first position, like for instance in (21a) and (21b), but it displays the form nun in a specific clause type.

To summarize, the data suggest that in these varieties the form nun/non is used instead of $u n$ if there is a complementizer or in yes/no questions.

\subsection{A Tentative Analysis}

The alternation we described in the previous section is a very interesting case of allomorphy induced by the syntactic environment. Even if the phenomenon needs a dedicated in-depth study, with the collection of data also from other varieties, we argue that it a case of a more general phenomenon that can be labeled "structural parasitism".

16 It should be pointed out that chi and pi trigger "Raddoppiamento Fonosintattico" (RF), that is the gemination of the following consonant, so it could be argued that the (re)instatement of the nasal is related to the phonological environment. However, this is not the case for $d i$, that does not cause the RF. Further research on this topic will have to take into consideration also all the potentially relevant phonological factors. 
With this term we refer to structures where the overt realization of certain structural positions automatically triggers the overt realization of other positions in their structural proximity. A phenomenon of this type described in Italian regards the clusters of resumptive clitics in clitic left dislocation constructions. As observed by Benincà (1988: 177-178), when an argument different from the direct object is topicalized, the resumptive clitic is optional and normally, if present, is felt as strongly redundant, as in examples (25a) and (25c). However, if there is another clitic in the preverbal space, the resumptive clitic can be used without triggering this "redundancy" effect. Thus, examples (25b) and (25d) are perfectly natural:
a. A Giorgio, gli regalo un libro.
(B's ex. (136))
to George to.him=donate.1SG a book
'To George, I donate a book.'
b. A Giorgio, glielo regalo volentieri. to George to.him=it=donate.1SG gladly
'To George, I donate it gladly.'
c. Dei suoi lavori, non ne parla mai. of.the his works not of.them=talks never
'About his works, he never talks.'
d. Dei suoi lavori, non me ne parla mai.
of.the his works not to.me $=$ of.them=talks never
'About his works, he never talks to me.'

This distribution suggests that the presence of another clitic in the preverbal clitic space "opens" that structural layer allowing the presence of non-redundant doubling clitics.

In the case of the un/nun alternation in dialects like those of Sciacca and S. Biagio Platani, some refinements are required. In general, from the corpus data, it is not clear if the Sicilian phenomenon has the same optionality character of oblique clitics in (25), that is if nun can appear even if there is not another element preceding it. Comparing these dialects with other Sicilian varieties, we assume that the form nun is complex like the preverbal negation of East Sicily. However, in this latter case, the complex $/ \mathrm{n} / / \mathrm{un} /$ is located below the CP layer, since it interacts only with object clitics before the verb. In the cases we are observing here, however, the initial $/ \mathrm{n}-/$ morpheme is present only when the $\mathrm{C}^{\circ}$ head is realized (or one of Force ${ }^{\circ}$ and Fin ${ }^{\circ}$ in Rizzi's (1997) terms). The $\mathrm{CP}$ can be activated by either a complementizer, as in the case of embedded clauses, or by the verb, as in the case of imperative and interrogative clauses. However the $/ \mathrm{n} /$ morpheme cannot be spelled out unless something else already occurs in the left periphery of the clause. The null hypothesis is the one represented in (26), where the /n/ morpheme occupies a negative head in the CP. What is important here is that: a) the occurrence of the $/ \mathrm{n} /$ morpheme cannot be explained by means of a phonological rule; b) $/ \mathrm{n} /$ is only spelled out when the CP is active. This means that the allomorphy /un/ versus /nun/ in Sciacca and S. Biagio Platani is of syntactic origin and the complex form $/ n-u n /$ is produced at the PF level, that is post-syntactically.

$$
\left[\text { Force }^{\circ} \text { chi }\left[\mathrm{CNeg}^{\circ} n-\left[\mathrm{Neg}^{\circ}-\text { un }[\mathrm{TP}]\right]\right]\right]
$$

The fact that nun is used in yes/no questions, like in (24), can be accounted for by assuming that in this clause type there is an active InterrogativeP position in the CP, containing an interrogative operator, that triggers the presence of the $\mathrm{CNeg}$ head. This is 
represented in (27). It is not excluded, but it is not possible to demonstrate it independently, that the complex negative marker moves by cyclical head movement, as required by the HMC, to the Interrogative head:

$$
\text { [InterrogativeP OP } \left.\left[\mathrm{CNeg}^{\circ} n-\left[\mathrm{Neg}^{\circ}-\text { un }[\mathrm{TP}]\right]\right]\right]
$$

The examples in (23) suggest that the presence of a phonetically realized subject blocks the "structural parasitism" mechanism. This point will have to be considered in more detail with further data collection, as in the ASIt corpus there is an example where the form nun appears after a complementizer and a personal pronoun used as subject: ${ }^{17}$

$$
\begin{aligned}
& \text { Chirinu chi io nun sia capaci. (Sciacca) } \\
& \text { believe.3PL that I not am able } \\
& \text { 'They believe that I cannot do that.' }
\end{aligned}
$$

It can be hypothesized that in some cases the subject is a topic in a TopicP position in the CP layer, but this hypothesis calls for independent evidence.

To summarize, in this section we have proposed to analyze the un/nun alternation of some Sicilian dialects as the result of a "structural parasitism" phenomenon, which can be seen at work also in other domains. While we are not proposing here a complete account for this mechanism (which should go back to more general economy principles), it is interesting to notice that it can target negation and that, more importantly, it shows that these varieties have a negative position also at the CP level. This is discussed in the next section.

\section{Negation in the $C P$}

We have described two very different negative items found in some Sicilian varieties: the first is a non-standard pre-verbal negative adverb that is used as a "wrong expectation" negation, i.e. to negate the relevance of an assertion; the second is a morphologically complex preverbal clitic negation marking standard negation, whose higher morpheme $n$ - is only lexicalized if the CP is already filled by some other element. We have also argued that these two items, neca and the head $n$ - in $n$-un, have something in common as we have tried to show that these two elements, besides being merged in the left periphery of the clause, are cases of what we have called "syntactic parasitism". The terms "parasitic" and "parasitism" have been used to describe very heterogeneous facts in formal syntax (cf., among other, terms like "parasitic gap", Engdahl (1983), or "parasitic licensing", den Dikken (2006)). Here, we use it to describe cases where either the position is "borrowed" from another type of category (i.e. Focus) or the presence of a given negative morpheme is licensed by the presence of a different item in a proximate structural position. We are aware that the pure labeling as "parasitism" of these phenomena represents a preliminary analysis and that it is necessary to find comparable phenomena in order to refine the idea in more abstract terms. However, some important consequences of the analysis can be mentioned already at this stage. We have made three points. The first point concerns a general observation:

$17 \quad$ In the ASIt database we have not found examples with negation and a referential subject in preverbal position, but, as shown by (21c), in the variety of S. Biagio Platani in this case the form of the negation is $u n$. 
across languages negation can be encoded by different lexical items and in different positions in the clause structure. This is not only true typologically but also at a microcomparative level. This is a potential problem for any syntactic theory based on the idea that semantic features have a one-to-one structural counterpart. The case of neca, that is the case of an element associated with [focus] encoding negation, is one of many cases suggesting that negation is not a simple element (that is a simple [neg] feature or a unique NegP position) but a complex one, formed as the result of the interaction of several abstract processes.

In some cases, this is easily observable in synchrony. In many languages, inanimate negative quantifiers or n-words can be used as negations (it can be assumed that this is possible precisely because these elements are associated with one of the features forming negation; see Bayer (2009) for some discussion on this). More often, however, this can be observed in diachrony, with the re-analysis and the grammaticalization of different items as negations. It can be argued, then, that what we call "feature parasitism" is a possible realization of a more general component of grammaticalization processes where syntactic items undergo the loss of some of their features and a re-analysis based on the surviving features.

Finally, the case of "structural parasitism" we have observed ( $n$ - appearing with the presence of a higher head) and the one we have compared it with (resumptive pronouns) seem to be the result of some more general principle. It is important to point out that economy principles are normally invoked in order to explain why something can be missing or avoided, while in these cases it appears to be exactly the opposite: the merging of a certain item allows the presence of another item "for free". The two cases analyzed here suggest that the application domain of this principle is limited to immediately adjacent positions (in the case of the clitic field) or at least the same structural layer (in the case of $n$-un). It is also interesting to note that in both cases the principle seems to concern heads. These general considerations should be tested when searching for similar phenomena.

\section{References}

Bayer, Josef. 2009. 'Nominal Negative Quantifiers as Adjuncts'. The Journal of Comparative Germanic Linguistics 12: 5-30. http://dx.doi.org/10.1007/s10828-009-9023-y

Belletti, Adriana. 2008. 'Answering Strategies: New Information Subjects and the Nature of Clefts'. In A. Belletti, Structures and Strategies, New York: Routledge, 242-265. http://dx.doi.org/10.4324/9780203887134

Benincà, Paola. 1988. 'L'ordine degli elementi nella frase'. In L. Renzi et al. (eds.), Grande grammatica italiana di consultazione. Vol. 1, Bologna: Il Mulino, 115194.

Bernini, Giuliano. 1992. 'Forme concorrenti di negazione in italiano'. In B. Moretti, D.Petrini, S. Bianconi (eds.), Linee di tendenza dell'italiano contemporaneo. Atti del XXIV Congresso della Società di Linguistica Italiana. Roma: Bulzoni, 191-215.

Cattaneo, Andrea. 2009. It is All About Clitics: The Case of a Northern Italian Dialect like Bellinzonese. Ph.D. thesis, New York University.

Churchward, C. M. 1953. Tongan Grammar. London: Oxford University Press.

Cinque, Guglielmo .1976. 'Mica'. Annali della Facoltà di Lettere e Filosofia dell'Università di Padova 1: 101-112. 
Croft, William. 1991. 'The Evolution of Negation'. Journal of Linguistics 27: 1-27. http://dx.doi.org/10.1017/s0022226700012391

Cruschina, Silvio. 2010. 'Aspetti morfologici e sintattici degli avverbi in siciliano'. Quaderni di lavoro dell'ASIt 11: 19-39.

Cruschina, Silvio. 2015. 'The Expression of Evidentiality and Epistemicity: Cases of Grammaticalization in Italian and Sicilian." Probus 27: 1-31. http://dx.doi.org/10.1515/probus-2013-0006

Delahunty, Gerald P. 1995. 'The Inferential Construction'. Pragmatics 5.3: 341-364. http://dx.doi.org/10.1075/prag.5.3.03del

Delahunty, Gerald P. and Laura Gatzkiewicz. 2000. 'On the Spanish Inferential Construction ser que'. Pragmatics 10.3: 301-322. http://dx.doi.org/10.1075/prag.10.3.01del

den Dikken, Marcel. 2006. 'Parasitism, Secondary Triggering, and Depth of Embedding'. In R. Zanuttini, H. Campos, E. Herburger \& P.H. Portner (eds), Cross-linguistic Research in Syntax and Semantics: Negation, Tense, and Clausal Architecture, Washington, DC: Georgetown University Press, 151-174.

Engdahl, Elisabet. 1983. 'Parasitic Gaps'. Linguistics and Philosophy 6: 5-34. http://dx.doi.org/10.1007/bf00868088

Garzonio, Jacopo and Cecilia Poletto. 2010. 'Quantifiers as Negative Markers in Italian Dialects'. In J. Van Croenenbroeck (ed.), Linguistics Variation Yearbook 2009, Amsterdam: Benjamins, 127-152. http://dx.doi.org/10.1075/livy.9.04gar

Garzonio, Jacopo and Cecilia Poletto. 2014a. 'The Negative Marker that Escaped the Cycle: some Notes on manco'. In C. Contemori and L. Dal Pozzo (eds.), Inquiries into Linguistic Theory and Language Acquisition. Papers offered to Adriana Belletti, Siena: CISCL Press, 181-197.

Garzonio, Jacopo and Cecilia Poletto. 2014b. 'The Dynamics of the PF Interface: Negation and Clitic Clusters'. Lingua 147: 9-24. http://dx.doi.org/10.1016/j.lingua.2013.11.002

Giorgi, Alessandra. 2010. About the Speaker: Towards a Syntax of Indexicality, Oxford: Oxford University Press. http://dx.doi.org/10.1093/acprof:oso/9780199571895.001.0001

Harris, Alice and Lyle Campbell. 1995. Historical Syntax in Cross-Linguistic Perspective. Cambridge: Cambridge University Press. http://dx.doi.org/10.1017/cbo9780511620553

Jaberg, Karl and Jakob Jud. 1928-1940. Sprach-und Sachatlas Italiens und der Südschweiz, Zofingen: Ringier, 8 volumes.

Ledgeway, A. 2015. 'Marking Presuppositional Negation in the Dialects of Southern Italy'. Ms., Cambridge University.

Manzini, M. Rita and Leonardo Savoia. 2005. I dialetti italiani e romanci, Morfosintassi generativa, Alessandria: Edizioni dell'Orso, 3 volumes.

Marotta, Giovanna. 2002-2003. 'Una nota sulla "lex Porena" in romanesco'. L'Italia dialettale 63-64: 87-103.

Miestamo, Matti. 2007. 'Negation - An Overview of Typological Research'. Language and Linguistics Compass 1.5: 552-570. http://dx.doi.org/10.1111/j.1749-818x.2007.00026.x

Munaro, Nicola and Jean-Yves Pollock. 2005. 'Qu'est-ce que (qu')-est-ce que? A Case Study in Comparative Romance Interrogative Syntax'. In G. Cinque and R. S. Kayne (eds.), Handbook of Comparative Syntax, Oxford and New York: Oxford University Press, 542-606. 
http://dx.doi.org/10.1093/oxfordhb/9780195136517.001.0001

Payne, John. R. 1985. 'Negation'. In: T. Shopen (ed.) Language Typology and Syntactic Description, Volume I, Clause Structure, Cambridge, UK: Cambridge University Press, 197-242.

Penello, Nicoletta and Diego Pescarini. 2008. 'Osservazioni su mica in italiano e alcuni dialetti veneti'. Quaderni di lavoro dell'ASIt 8: 43-56.

Poletto, Cecilia. 2008. 'On Negation Splitting and Doubling'. Ms., University of Venice.

Poletto, Cecilia. 2010. 'The Syntax of Focus Negation'. Quaderni di lavoro dell'ASIt 10: 39-62.

van der Auwera, Johan. 2009. 'The Jespersen Cycles'. In E. van Gelderen (ed.), Cyclical Change, Amsterdam: Benjamins, 35-72. http://dx.doi.org/10.1075/la.146

van der Auwera, Johan. 2010. 'On the Diachrony of Negation. In L. Horn (ed.), The Expression of Negation. Berlin: Mouton De Gruyter, 73-109. http://dx.doi.org/10.1515/9783110219302

van Gelderen, Elly. 2004. Grammaticalization as Economy. Amsterdam: Benjamins. http://dx.doi.org/10.1075/la.71

Willis, David, Christopher Lucas and Anne Breitbarth (eds.). 2013. The History of Negation in the Languages of Europe and the Mediterranean. Oxford: Oxford University Press.

http://dx.doi.org/10.1093/acprof:oso/9780199602537.001.0001

Zanuttini, Raffaella. 1997. Negation and Clausal Structure: a Comparative Study of Romance Languages, Oxford and New York: Oxford University Press. 